\title{
Análise dos investimentos sociais da Petrobrás - uma comparação dos anos 2013 e 2018
}

\author{
Petrobrás social investiment analysis - a comparison between 2013 \\ and 2018
}

1 Catiana Aparecida da Silveira da Cunha

2 Riatla Oliveira da Silva riatla.oliveira@hotmail.com

3 Úrsula Adriane Fraga Amorim

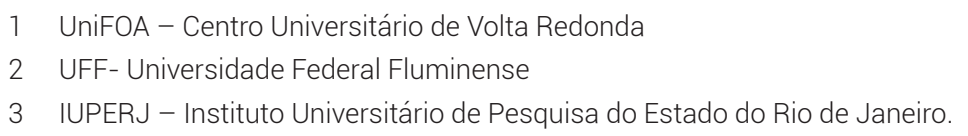

\section{Resumo}

A Contabilidade é uma ciência social aplicada que busca, através da sua função social, prestar informações sobre as relações das empresas com a sociedade na qual está inserida, em um mesmo contexto social. Sendo assim, o objetivo do presente trabalho foi o de identificar o grau em investimentos sociais da Petrobrás em um comparativo de intervalo de 5 anos. Para identificar o referido grau, foram utilizados os valores divulgados, pela empresa em investimento social sobre a receita de vendas consolidada e o lucro antes do imposto de renda e contribuição social. A pesquisa mostrou que não há auditoria das informações. Foram encontradas informações sobre investimentos sociais com a mensuração de tributos incluídos dentro desses valores (excluindo os encargos sociais), prejudicando a apuração do grau em investimentos sociais. A empresa faz investimentos socioambientais, não identificando os valores sociais e os ambientais e realiza também os investimentos ambientais, que foram levados em consideração.

\section{Palavras-chave}

Contabilidade. Investimentos sociais. Responsabilidade social.

\section{Abstract}

Accounting is an applied social science that seeks, through its social function, to provide information on the relationships of companies with the society in which it is inserted, in the same social context. Therefore, the objective of the present work was to identify the degree in social investments of Petrobrás in a comparative interval of 5 years. To identify this degree, the values disclosed by the company in social investment on consolidated sales revenue and profit before income tax and social contribution were used. The research showed that there is no audit of the information. Information on social investments was found with the measurement of taxes included within these values (excluding social charges), impairing the calculation of the degree in social investments. The company makes social and environmental investments, not identifying social and environmental values and also makes environmental investments, which were taken into account.

\section{Keywords}

Accounting. Social investments. Social responsability.

\section{Como você deve citar?}

CUNHA, Catiana Aparecida da Silveira da; SILVA, Riatla Oliveira da; AMORIM, Úrsula Adriane Fraga. Análise dos investimentos sociais da Petrobrás - uma comparação dos anos 2013 e 2018. Cadernos UniFOA, Volta Redonda, n. 43 , p. $75-84$, agosto 2020 . 


\section{INTRODUÇÃO}

O presente estudo tem como proposta a verificação do grau em investimentos sociais da Petrobrás em comparativo de intervalo de cinco anos. Para tanto, elege-se como objetivo analisar os investimentos sociais da empresa. Diante do exposto, surgiu a necessidade de se investigar a relação de uma das empresas mais conhecidas do país, perante a sociedade, visando à redução das demandas sociais. Dessa forma, o presente trabalho tem como questionamento se a empresa Petróleo Brasileiro S.A - Petrobras faz investimentos sociais visando atender à demanda da sociedade.

O tema é relevante, pois a Petrobrás está inserida na sociedade e, como parte dela, interage com os outros agentes da comunidade (pessoas, governo e meio ambiente). A Contabilidade é uma ciência social aplicada, tendo como uma de suas premissas refletir sobre as relações entre os diversos indivíduos ou entidades de uma sociedade. Sendo assim, busca, através da sua função social, prestar informações sobre as relações das empresas com a sociedade na qual está inserida em um mesmo contexto social (SANTOS, 2003).

Nesse sentido, Cunha (2002) afirma que a Contabilidade procura mostrar essas relações entre empresa e sociedade, para evidenciar tanto o investimento social feito por elas como o benefício da melhoria da qualidade de vida dos beneficiados.

Sendo assim, a Contabilidade deve estar atenta aos interesses dos seus usuários e procurar, através da sua função social, "estudar as influências das variações patrimoniais não apenas nas entidades, mas também na sociedade e no meio ambiente" (KROETZ, 1999, p. 9).

Para Tachizawa (2002, p. 21), "as demandas sociais que a própria comunidade repassa às organizações tendem a induzir um novo posicionamento por parte dos empresários e executivos em face de tais questões".

Para alcance dos objetivos propostos, optou-se por realizar pesquisa bibliográfica e documental por meio de informações gerenciais originadas de empresas e associações.

\section{METODOLOGIA}

Na elaboração deste trabalho, optou-se pelos métodos de pesquisa bibliográfica e dados obtidos do balanço social e das demonstrações financeiras da empresa, pois trata-se de uma estratégia de pesquisa necessária para a elaboração e condução de qualquer pesquisa científica, visando à construção da plataforma teórica do estudo. Como descrito por Martins e Theóphilo (2009, p.54),

uma pesquisa bibliográfica procura explicar e discutir um assunto, tema ou problema com base em referências publicadas em livros, periódicos, revistas enciclopédias, dicionários, jornais, sites, cds, anais de congressos etc. Busca conhecer, analisar e explicar contribuições sobre determinado assunto, tema ou problema.

Vergara (2007, p.48) enfatiza que a pesquisa bibliográfica é o estudo sistematizado desenvolvido com base em material publicado em livros, revistas, jornais, redes eletrônicas, isto é, material acessível ao público em geral. Fornece instrumental analítico para qualquer outro tipo de pesquisa, mas também pode esgotar-se em si mesma.

No que diz respeito à pesquisa documental, os autores a definem 
a estratégia de pesquisa documental é característica dos estudos que utilizam documentos como fonte de dados, informações e evidências. Os documentos são dos mais variados tipos, escritos ou não, tais como: diários; documentos arquivados em entidades públicas e privadas; gravações; correspondências pessoais e formais; fotografias; filmes; mapas etc. (MARTINS e THEÓPHILO; 2009, p. 55).

Como se pode observar, as duas formas de pesquisas, tanto a pesquisa documental quanto bibliográfica, são bem semelhantes, diferenciando-se apenas pela natureza de suas fontes, já que a pesquisa documental utiliza materiais advindos do próprio autor do trabalho que ainda não passaram por análise ou que podem ser reelaborados conforme a necessidade do que está sendo pesquisado e a pesquisa bibliográfica utiliza obras já realizadas e que não podem ser mais alteradas.

\section{A CONTABILIDADE E A SOCIEDADE}

\subsection{Responsabilidade social}

A contabilidade aplicada a forma de função social tem como base uma análise também por parte das organizações, tendo suas respectivas responsabilidades sociais corporativas. Hoje, a contabilidade pode mensurar essas informações, disponibilizadas pelas próprias empresas em suas demonstrações financeiras e relatórios à sociedade. Dentre esses relatórios, existem o balanço social e o modelo GRI - Global Reporting Initiative.

Para o Banco Mundial (2002 apud Kreitlon 2004), a responsabilidade social empresarial é

o compromisso de contribuir para o desenvolvimento econômico sustentável trabalhando em conjunto com os empregados, suas famílias, a comunidade local e a sociedade em geral para melhorar sua qualidade de vida de forma que seja bom tanto para as empresas como para o desenvolvimento (KREITLON, 2002, p. 3).

As empresas buscam atender a sua missão, valores e objetivos, concomitantemente com seu lucro. Logicamente, em um mundo globalizado, atos inconsequentes de organizações afetam não somente a si própria e seus funcionários, mas também ambiente e sociedade. Com vistas a um novo modo de empreender e administrar, organizações buscam utilizar uma nova forma de gestão, buscando uma responsabilidade por seu ato no ambiente e sociedade, pois fazem parte deles.

Como algo que vem sendo debatido e com a devida importância que o tema sobre sustentabilidade tem alcançado, a BM\&FBOVESPA, em 2005, implantou o Índice de Sustentabilidade Empresarial - ISE, que "busca criar um ambiente de investimento compatível com as demandas de desenvolvimento sustentável da sociedade contemporânea e estimular a responsabilidade ética das corporações".

O ISE é, também,

uma ferramenta para análise comparativa da performance das empresas listadas na BM\&FBOVESPA sob o aspecto da sustentabilidade corporativa, baseada em eficiência econômica, equilíbrio ambiental, justiça social e governança corporativa. Também amplia o entendimento sobre empresas e grupos comprometidos com a sustentabilidade, diferenciando-os em termos de qualidade, nível de compromisso com o desenvolvimento sustentável, equidade, transparência e prestação de contas, natureza do produto, além do desempenho empresarial nas dimensões econômico-financeira, social, ambiental e de mudanças climáticas. (BM\&FBOVESPA, s.d.).

O Conselho Deliberativo do ISE - CISE (Conselho Deliberativo do Índice de Sustentabilidade Empresarial), órgão máximo de governança do ISE, tem como missão garantir um processo transparente de construção do índice e de seleção das empresas. Atualmente, o CISE é composto por onze instituições: B3, APIMEC, ANBIMA, ABRAPP, ETHOS, IBGC, IBRACON, IFC, GIFE, MMA e ONU Meio Ambiente. 
Com vistas a uma boa relação da empresa com a sociedade, torna-se necessário que sejam amplamente divulgadas as informações de responsabilidade social empresarial.

\title{
3.2 Balanço social
}

Balanço social é definido como

um instrumento de gestão e de informação que visa evidenciar, da forma mais transparente possível, informações econômicas e sociais, do desempenho das entidades, aos mais diferenciados usuários, entre estes, os funcionários (TINOCO, 2006, p. 14)

O BNDES (2000) define o Balanço Social como

\begin{abstract}
a publicação de um conjunto de informações e de indicadores dos investimentos e das ações realizadas pelas empresas no cumprimento de sua função social junto aos seus funcionários, ao governo e às comunidades com que interagem, direta e indiretamente. Desta forma, o Balanço Social é um instrumento de demonstração das atividades das empresas, que tem por finalidade conferir maior transparência e visibilidade às informações que interessam não apenas aos sócios e acionistas das companhias (shareholders), mas também a um número maior de atores: empregados, fornecedores, investidores, parceiros, consumidores e comunidade (stakeholders) (BNDES-03, 2000)
\end{abstract}

Desse modo, ele se torna importante ferramenta para os usuários e qualquer pessoa que queira obter informações sobre a relação da empresa com a sociedade, trazendo de modo claro e coeso essa interação.

\subsection{Investimento social}

O Instituto para o Desenvolvimento do Investimento Social - IDIS, uma Organização da Sociedade Civil de Interesse Público (OSCIP) define como investimento social corporativo "a alocação voluntária e estratégica de recursos da empresa, para o benefício público".

Para o Grupo de Instituições Fundações e Empresas (GIFE), o investimento social privado é "o repasse voluntário de recursos privados de forma planejada, monitorada e sistemática para projetos sociais, ambientais e culturais de interesse público". (GIFE, 1995).

A divulgação das ações de responsabilidade social, bem como os investimentos sociais através de relatórios anuais são as fontes necessárias para a comunicação entre a empresa e a sociedade.

\section{O CASO PETROBRÁS: A CRISE DA LAVA JATO}

\subsection{Petrobrás e sua natureza jurídica}

A Petrobrás é uma empresa de economia mista e o acionista majoritário é a União Federal, que mantém o controle.

A Petróleo Brasileiro S.A - Petrobras dedica-se diretamente ou por meio de suas subsidiárias, à pesquisa, refino, lavra, processamento, comércio e transporte de petróleo proveniente de poço, de xisto ou de outras rochas, de seus derivados, de gás natural e de outros hidrocarbonetos fluídos, além das atividades vinculadas à energia, podendo promover pesquisa, desenvolvimento, produção, transporte, distribuição e comercialização de todas as formas de energia, bem como quaisquer outras atividades correlatas ou afins. 
Líderes da indústria petrolífera no Brasil também mantêm atividades na Argentina, na Bolívia, na Colômbia, nos Estados Unidos, no México, no Nigéria, no Paraguai e no Uruguai. Segundo notícias da própria Empresa em suas informações aos acionistas no ranking "As Marcas mais Valiosas do Brasil", elaborado pela consultoria BrandAnalytics/Millward Brown, a marca obteve a segunda colocação entre as marcas mais valiosas do Brasil, com o valor de US\$ 5,7 bilhões. Também comenta sobre outra pesquisa, a Interbrand, consultoria global que cria e gerencia valor de marca, que estamos em quinto lugar entre as "marcas brasileiras mais valiosas", ultrapassando $\mathrm{R} \$ \mathbf{8 , 7}$ bilhões.

\subsection{Crise da Petrobrás e lava jato.}

A empresa, em 2013, criou um mecanismo de anticorrupção e fraudes, para evitar que a marca Petrobrás fosse manchada ou tivesse seu valor desvalorizado no mercado internacional, com o intuito de prevenir, detectar e corrigir desvios de fraudes e corrupção. Três ações fundamentam o programa e sua aplicação: prevenção, através de políticas claras e educativas quanto à importância da ética em todas as ações; detecção, com mecanismos capazes de identificar tentativas de fraude e atos de corrupção; e sistema de consequências, com a correção de problemas já ocorridos.

Com a criação desse mecanismo, já se evidenciava, em 2013, pela própria administração, que poderia estar ocorrendo fraudes e corrupção dentro da empresa. No ano 2015, a $8^{\text {a }}$ fase da operação "Lava Jato", investigação de corrupção e fraudes no governo, atingiu diretamente a Petrobrás, influenciando nas ações e colocando suas demonstrações financeiras para nova avaliação de riscos e valores.

Comparativamente, esses escândalos influenciaram na marca da Petrobrás, a qual sempre esteve ligada ao prestígio e boas relações. Dessa forma, é necessário verificar se a empresa, após esses escândalos, visou atender à demanda da sociedade e conjuntamente atingir seus objetivos.

Em 2018, a Petrobrás divulgou em seu relatório de sustentabilidade que continuou com mecanismo de anticorrupção, ampliando-o com o ciclo contínuo de treinamentos obrigatórios, chamado "Trilha Compromisso com a Conformidade", que ajuda os colaboradores a identificar riscos de compliance e a como agir nessas situações. 0 treinamento é realizado na modalidade de Ensino a Distância (EAD) e envolve a alta administração, os gestores, os consultores e os empregados de todas as carreiras. Foi concluída, nesse mesmo ano, a adequação do Portal de Transparência aos requisitos previstos na Lei das Estatais número 13.303/16 e em outros normativos, ampliando o escopo e o detalhamento das informações disponibilizadas.

\section{RELATÓRIOS DE DIVULGAÇÃO DOS INVESTIMENTOS SOCIAIS DA PETROBRÁS E RESPONSABILIDADE SOCIAL}

As empresas utilizam diferentes relatórios para a divulgação de informações sobre seus investimentos. São eles: as Demonstrações Contábeis, o GRI - Global Reporting Initiative, o Relatório de Sustentabilidade, o modelo IBASE (Instituto Brasileiro de Análises Sociais e Econômicas) de Balanço Social.

A Petrobrás utiliza, como relatório de divulgação dos iinvestimentos sociais, os modelos de Balanço Social - IBASE, Demonstrações Financeiras e Relatório de Sustentabilidade. Nesses termos, precisamos entender que as contas analisadas são somente as de investimentos sociais.

Em 2013, no seu balanço social, divulgou os seus números e informações referentes ao seu relatório de sustentabilidade. Nesse ano, a empresa possuía uma receita de vendas consolidada em R\$304.890.000.000,00, com um lucro antes da participação no lucro e impostos consolidados (R0) de $R \$ 29.257 .000 .000,00$ e a folha de pagamento bruta consolidada (FPB) de R\$27.025.000.000,00. 
Já em relação aos indicadores internos, como alimentação, encargos sociais compulsórios, previdência privada, saúde, segurança e saúde no trabalho, educação, cultura, capacitação e desenvolvimento profissional, creche ou auxílio-creche, participação nos lucros ou resultados e outros, em 2013 , foi de $\mathrm{R} \$ 11.479 .000 .000,00$, com $42,51 \%$ sobre a folha de pagamento bruta consolidada (FPB) e $3,75 \%$ sobre a receita de vendas consolidada (RL).

Os indicadores sociais externos, como geração de renda e oportunidades de trabalhos, educação para qualificação profissional, garantia dos direitos da criança e do adolescente, cultura, esporte e outros, incluindo os tributos (excluídos os encargos sociais) somam, em 2013, R\$ 102.182.000.000,00, tendo $349,26 \%$ sobre o RO e $33,51 \%$ sobre RL, conforme Balanço Social abaixo:

Tabela 1 - Balanço Social 2013.

\begin{tabular}{|c|c|c|c|}
\hline 1-BASE dE CÁLCULO & \multicolumn{3}{|c|}{2013 Valor (R\$ milhões) } \\
\hline Receita de vendas consolidada (RL) & & & 304.890 \\
\hline Lucro antes da participação no lucro e impostos consolidados (RO) & & & 29.257 \\
\hline Folha de pagamento bruta consolidada (FPB) & & & 27.025 \\
\hline 2 -INDICADORES SOCIAIS INTERNOS & Valor & \% sobre FPB & \% sobre RL \\
\hline Alimentação & 1.063 & $3,93 \%$ & $0,35 \%$ \\
\hline Encargos sociais compulsórios & 5.366 & $19,85 \%$ & $1,76 \%$ \\
\hline Previdência privada & 1.674 & $6,20 \%$ & $0,55 \%$ \\
\hline Saúde & 1.266 & $4,68 \%$ & $0,42 \%$ \\
\hline Segurança e saúde no trabalho & 221 & $0,82 \%$ & $0,07 \%$ \\
\hline Educação & 215 & $0,80 \%$ & $0,07 \%$ \\
\hline Cultura & 20 & $0,07 \%$ & $0,01 \%$ \\
\hline Capacitação e desenvolvimento profissional & 423 & $1,57 \%$ & $0,14 \%$ \\
\hline Creches ou auxilio-creche & 39 & $0,14 \%$ & $0,01 \%$ \\
\hline Participação nos lucros ou resultados & 1.102 & $4,08 \%$ & $0,36 \%$ \\
\hline Outros & 90 & $0,33 \%$ & $0,03 \%$ \\
\hline Total - Indicadores sociais internos & 11.479 & $42,51 \%$ & $3,75 \%$ \\
\hline 3-INDICADORES SOCIAIS EXTERNOS & Valor & \% sobre RO & \% sobre RL \\
\hline Geração de Renda e Oportunidade de Trabalho & 230 & $0,79 \%$ & $0,08 \%$ \\
\hline Educação para a Qualificação Profissional & 62 & $0,21 \%$ & $0,02 \%$ \\
\hline Garantia dos Direitos da Criança e do Adolescente " & 74 & $0,25 \%$ & $0,02 \%$ \\
\hline Cultura & 203 & $0,69 \%$ & $0,07 \%$ \\
\hline Esporte & 81 & $0,28 \%$ & $0,03 \%$ \\
\hline Outros & 25 & $0,09 \%$ & $0,01 \%$ \\
\hline Total das contribuições para a sociedade & 675 & $2,31 \%$ & $0,22 \%$ \\
\hline Tributos (excluídos encargos sociais) & 101.507 & $346,95 \%$ & $33,29 \%$ \\
\hline Total - Indicadores sociais externos & 102.182 & $349,26 \%$ & $33,51 \%$ \\
\hline
\end{tabular}

Fonte: Petrobrás, Balanço Social 2013.

Em 2018, empresa obteve uma receita de vendas consolidada em $\mathrm{R} \$ 349.836 .000 .000,00$ e $\mathrm{R} \$$ 43.776.000.000,00, para lucro antes da participação no lucro e impostos consolidados (R0) e a folha de pagamento bruta consolidada (FPB) R\$29.899.000.000,00.

Já em relação aos indicadores internos, como alimentação, encargos sociais compulsórios, previdência privada, saúde, segurança e saúde no trabalho, educação, cultura, capacitação e desenvolvimento profissional, creche ou auxílio-creche, participação nos lucros ou resultados e outros, esse valor foi de $\mathrm{R} \$ 15.707 .000 .000,00$, com $52,53 \%$ sobre a folha de pagamento bruta consolidada (FPB) e $4,49 \%$ sobre a receita de vendas consolidada (RL). 
Os indicadores sociais externos, como geração de renda e oportunidades de trabalhos, educação para qualificação profissional, garantia dos direitos da criança e do adolescente, cultura, esporte e outros, incluindo os tributos (excluídos os encargos sociais), somam o valor de R\$ 147.504.000.000,00, com $336,95 \%$ sobre o RO e $42,16 \%$ sobre a RL.

Tabela 2 - Balanço Social 2018

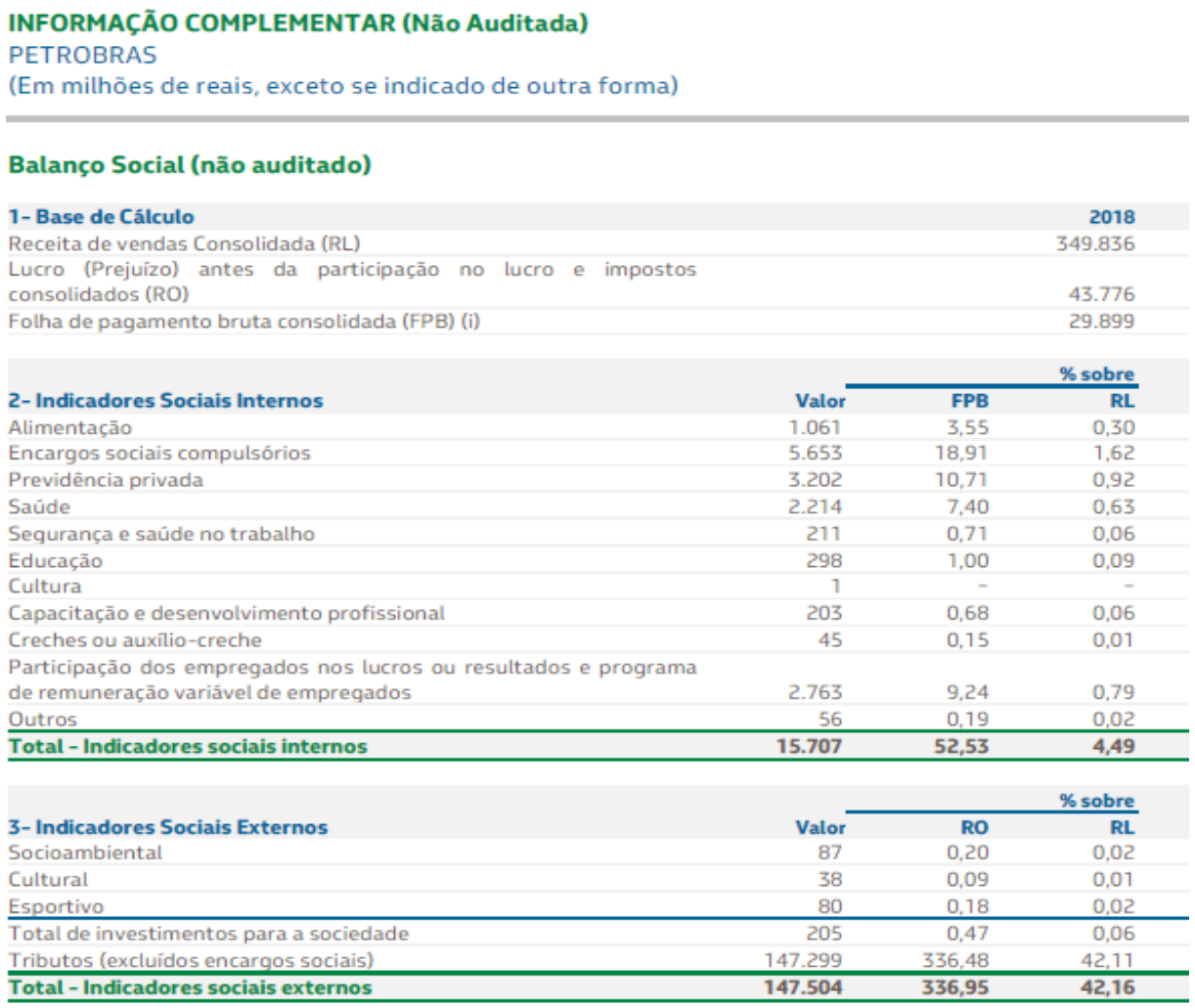

Fonte: Petrobrás, Balanço Social 2018

\subsection{Análise comparativa dos relatórios}

Em análise comparativa desses anos, percebemos que os indicadores sociais internos tiveram um aumento de $R \$ 4.228 .000 .000,00$ (36\% de aumento nos investimentos internos), pois, em 2013, era de $\mathrm{R} \$ 11.479 .000 .000,00$ e, em 2018, foi de R\$ 15.707.000.000,00.

Dentre os investimentos sociais externos, foram desmembrados os valores de investimentos para a sociedade e os tributos nesses investimentos (excluídos os encargos). Os investimentos sociais externos para sociedade, em 2013, eram de $R \$ 675.000 .000,00$, e os tributos, de $R \$ 101.507 .000 .000,00$, totalizando o valor de $\mathrm{R} \$ 102.182 .000 .000,00$.

No ano de 2018, os investimentos sociais para a sociedade foram de $\mathrm{R} \$ 205.000 .000,00$ e os tributos foram de $\mathrm{R} \$ 147.299 .000 .000,00$. Fazendo a comparação desses valores, os investimentos sociais para a sociedade tiveram uma redução de $\mathrm{R} \$ 470.000 .000,00$ (redução de $69 \%$ desse investimento). Já em relação aos tributos, ocorreu um aumento $\mathrm{R} \$ 45.792 .000 .000,00$ (45\% de aumento nos tributos). 
Gráfico 1 - Análise Petrobrás 2013 - 2018

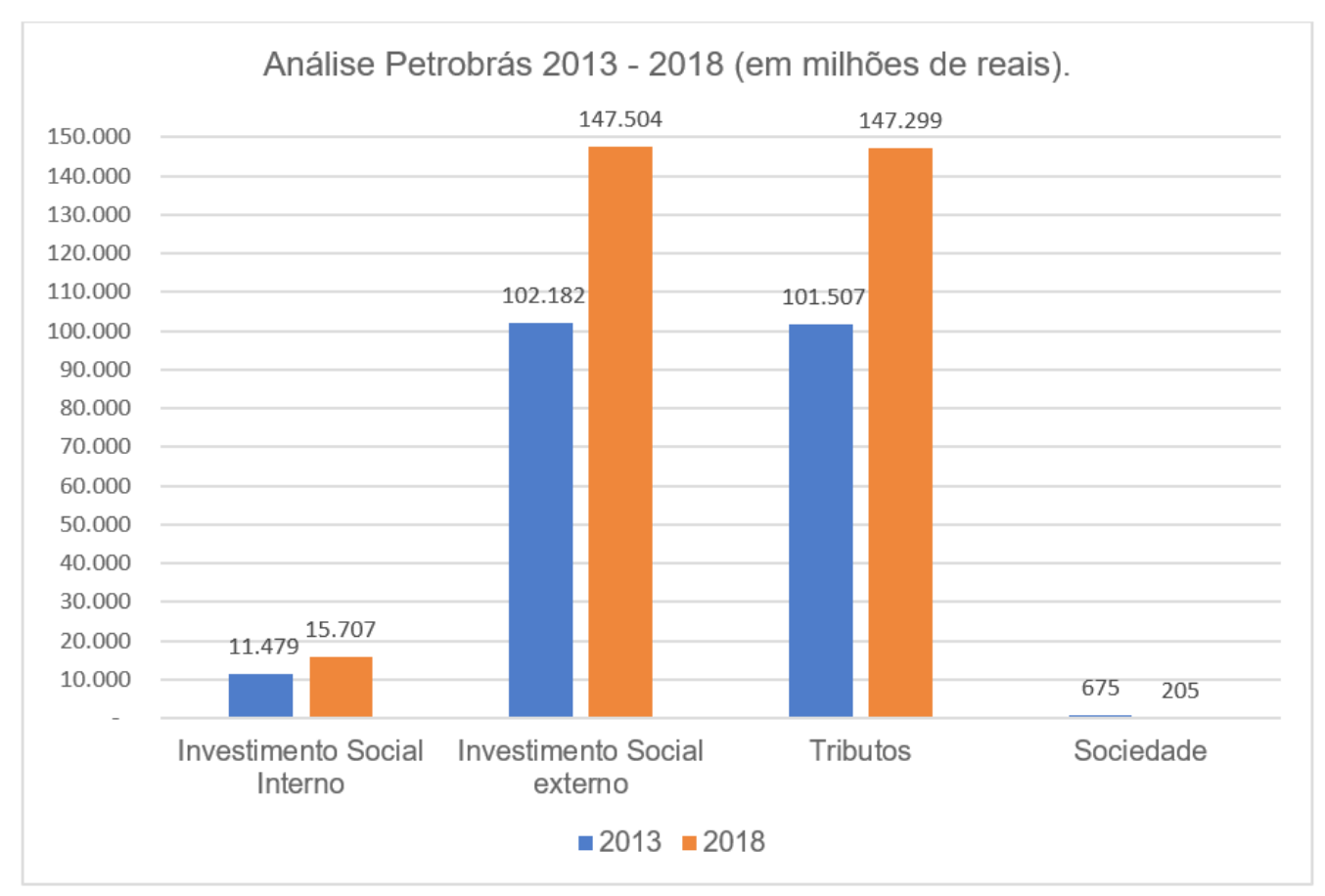

Fonte: Petrobrás, Demonstrações Financeiras 2013 e 2018.

Com base em denominadores comuns, foram feitas duas análises de grau de investimento da Petrobrás em relação a sua receita de vendas consolidadas e seu lucro antes do imposto de renda e contribuição social, conforme descrito abaixo.

Tabela 3 - Grau de Investimento Social com tributos.

\begin{tabular}{cccccc}
\hline \multicolumn{5}{c}{ Grau de Investimento Social - Considerando Tributos (em milhões de reais) } \\
\hline Ano & $\begin{array}{c}\text { Receita de Vendas } \\
\text { Consolidadas }\end{array}$ & $\begin{array}{c}\text { Lucro Antes do } \\
\text { Imposto de Renda e } \\
\text { Contribuição Social }\end{array}$ & $\begin{array}{c}\text { Investimentos } \\
\text { Sociais }\end{array}$ & $\begin{array}{c}\text { Investimento sobre } \\
\text { a Receita de Vendas } \\
\text { Consolidadas }\end{array}$ & $\begin{array}{c}\text { Investimento sobre } \\
\text { Lucro Antes do } \\
\text { Imposto de Renda e } \\
\text { Contribuição Social }\end{array}$ \\
\hline 2013 & 304.890 & 29.257 & 113.661 & $37 \%$ & $388,49 \%$ \\
\hline 2018 & 349.876 & 43.776 & 163.211 & $47 \%$ & $372,83 \%$ \\
\hline
\end{tabular}

Fonte: Petrobrás, Relatório de Sustentabilidade 2013 e 2018.

Tabela 4 - Grau de Investimento Social - Sem tributos.

\begin{tabular}{cccccc}
\hline \multicolumn{5}{c}{ Grau de Investimento Social - Desconsiderando os tributos (em milhões de reais) } \\
\hline Ano & $\begin{array}{c}\text { Receita de Vendas } \\
\text { Consolidadas }\end{array}$ & $\begin{array}{c}\text { Lucro Antes do } \\
\text { Imposto de Renda } \\
\text { e Contribuição } \\
\text { Social }\end{array}$ & $\begin{array}{c}\text { Investimentos } \\
\text { Sociais }\end{array}$ & $\begin{array}{c}\text { Investimento sobre } \\
\text { a Receita de Vendas } \\
\text { Consolidadas }\end{array}$ & $\begin{array}{c}\text { Investimento sobre } \\
\text { Lucro Antes do } \\
\text { Imposto de Renda e } \\
\text { Contribuição Social }\end{array}$ \\
\hline 2013 & 304.890 & 29.257 & 12.154 & $3,99 \%$ & $41,54 \%$ \\
\hline 2018 & 349.876 & 43.776 & 15.912 & $4,55 \%$ & $36,35 \%$ \\
\hline
\end{tabular}

Fonte: Petrobrás, Relatório de Sustentabilidade 2013 e 2018. 


\section{CONSIDERAÇÕES FINAIS}

A Contabilidade é uma Ciência Social aplicada, cujos relatórios são também instrumentos de diálogo da empresa com a sociedade na qual está inserida. Por esse motivo, a Contabilidade deve estar atenta aos interesses dessa sociedade na busca de informações.

Com vistas a contribuir para esse processo, a presente pesquisa teve como objetivo identificar o grau em investimentos sociais da Petrobrás em comparativo de intervalo de 5 anos. Cabe esclarecer que esse objetivo foi atingido com ressalvas, pois algumas informações demonstradas no Balanço Social não são auditadas, apesar de a Petrobrás utilizar da sua fé pública e demonstrar em seus relatórios essas informações.

Outro fato preocupante verificado foi a separação entre os investimentos sociais voluntários, dos investimentos de leis de incentivos e dos obrigatórios, ou seja, a empresa utiliza os tributos pagos ou por leis de incentivos como informação de investimentos sociais, com caráter voluntário.

O presente estudo não abordou os temas de investimento ambiental e os benefícios gerados para as entidades que divulgam essas informações, por considerar que será tema para trabalhos futuros a serem realizados.

Por meio do presente estudo e análise do grau de investimentos das empresas, percebe-se que os investimentos sociais realizados pela empresa podem ser enxergados de duas formas, se comparados com seus lucros de atividades operacionais. A primeira forma será de utilizar os tributos pagos como investimentos sociais. A segunda forma é desconsiderando esses tributos e apenas os investimentos feitos de formas voluntárias. Deve-se ressaltar que se buscam os investimentos sociais de forma voluntariada e, como se pode observar na análise, a empresa mensura os tributos como investimento social. Nota-se que os investimentos sociais das empresas de forma voluntariada são de valores muito menores.

\section{REFERÊNCIAS}

BANCO NACIONAL DE DESENVOLVIMENTO ECONÔMICO E SOCIAL. Balanço Social e Outros Aspectos da Responsabilidade Social Corporativa. Relato Setorial No 2. Área de Desenvolvimento Social - AS/ GESET. Rio de Janeiro: BNDES, 2000. Disponível em: http://www.bndes.gov.br/SiteBNDES/export/sites/ default/bndes_pt/Galerias/Arquivos/conhecimento/relato/social02.pdf. Acesso em: 01 jul. 2019.

BMF BOVESPA. Índice de Sustentabilidade Empresarial. Disponível em: http://www.bmfbovespa.com. $\mathrm{br} / \mathrm{pt}$ _br/produtos/indices/indices-de-sustentabilidade/indice-de-sustentabilidade-empresarial-ise. htm. Acesso em: 10 jul. 2019.

CUNHA, Jacqueline Venerosos Alves da. Demonstração contábil do valor adicionado - DVA: um instrumento de mensuração da distribuição da riqueza das empresas para os funcionários. Dissertação de mestrado - Faculdade de Economia e Contabilidade da Universidade de São Paulo. São Paulo: FEA/ USP, 2002.

GUERREIRO, Reinaldo. Modelo conceitual de sistema de informação de gestão econômica: uma contribuição à teoria da comunicação da contabilidade. São Paulo, Tese de Doutoramento, FEA-USP, 1989. 
GRUPO DE INSTITUIÇÕES FUNDAÇÕES E EMPRESAS - GIFE. 2014. Disponível em: https://www.gife. org.br/investimento-social-privado/. Acesso em: 01 maio 2019.

INSTITUTO PARA O DESENVOLVIMENTO DO INVESTIMENTO SOCIAL - IDIS. 2018. Disponível em: https:// www.idis.org.br/. Acesso em: 01 maio 2019.

KREITLON, Maria Priscilla. A Ética nas Relações entre Empresas e Sociedade: fundamentos teóricos da eesponsabilidade social empresarial. In: XXVIII ENANPAD, Curitiba, 2004.

KROETZ, Cesar Eduardo S. Contabilidade Social. Revista Contabilidade e Informação. Editora Unijuí. 01 de abril 1999. ljuí- RS

MARTINS, Gilberto de Andrade; THEÓPHILO, Carlos Renato. Metodologia da Investigação Cientifica para ciências sociais aplicadas. 2. ed. São Paulo: Atlas S.A. 2009.

PETROBRAS. Relação com Investidor. Demonstrações Financeiras da Petrobrás 2013. Disponível em: https://www.investidorpetrobras.com.br//ptb/8718/RA2013Portugues25fev2014.pdf Acesso em 01 maio 2019.

PETROBRAS. Relação com Investidor. Demonstrações Financeiras da Petrobrás 2018. Disponível em: https://www.investidorpetrobras.com.br//ptb/71/DFP_2018_interativo.pdf. Acesso em: 01 maio 2019.

PETROBRAS. Relação com Investidor. Relatório de Sustentabilidade da Petrobrás 2013. Disponível em: https://www.investidorpetrobras.com.br/ptb/8717/relatoriodesustentabilidade2013portugues. pdf. Acesso em 01 maio 2019.

PETROBRAS. Relação com Investidor. Relatório de Sustentabilidade da Petrobrás 2018. Disponível em: https://www.investidorpetrobras.com.br/ptb/83/Sustentabilidade_2018.pdf. Acesso em: 01 maio 2019.

SANTOS, Ariovaldo dos. Demonstração do valor adicionado: como elaborar e analisar a DVA. São Paulo: Atlas, 2003.

TACHIZAWA, Takeshy. Gestão ambiental e responsabilidade social corporativa. São Paulo: Atlas, 2002.

TINOCO, João Eduardo Prudêncio. Balanço social: uma abordagem da transparência e da responsabilidade pública das organizações. São Paulo: Atlas, 2006.

VERGARA, Sylvia Constant. Projetos e relatórios de pesquisa em administração. 9. ed. São Paulo: Editora Atlas, 2007. 